\title{
Analisis peran Employee Commitment sebagai Mediasi dalam Hubungan antara Leadership, Talent Management dan Employee Performance pada Karyawan
}

\author{
Johnson Hendry \\ Universitas Internasional Batam \\ johnsonhendry1@gmail.com
}

\author{
Dhita Hafizha Asri \\ Universitas Internasional Batam \\ dhita.hafizha@uib.ac.id
}

\begin{abstract}
Abstrak Kinerja karyawan merupakan hasil dari apa yang telah dicapai di tempat kerja dan sangat bergantung pada tingkat kinerja individu. Masalah krusial yang terkait dengan manajemen talenta di berbagai organisasi muncul sebagai tantangan sumber daya manusia utama yang dihadapi perusahaan di berbagai industri. Perusahaan penyedia jasa periklanan atau advertising agency, sebelum pandemic Covid ini memang berkembang cukup pesat di Batam. Pada saat ini di Indonesia dapat dengan mudah menemukan perusahaan advertising agency ini yang biasanya menyediakan jasa untuk perusahaan maupun perorangan untuk mempromosikan produk usahanya. Sampel penelitian ini sebanyak 250 responden yang bekerja pada perusahaan agen periklanan di Batam. Hasil penelitian menunjukkan terdapat hubungan yang signifikan pada semua variabel independen dan dependen yang diuji.
\end{abstract}

Kata Kunci Leadership, Talent Management, Employee Commitment, Employee Performance

\section{PENDAHULUAN}

Saat ini dimana pandemik Covid-19 sedang merebak, banyak perusahaan yang mengalami penurunan operasional dan kegiatan usaha. Hampir semua bidang usaha mengalami penurunan omset dan pendapatan termasuk juga perusahaan dibidang percetakan dan agen periklanan. Hal ini disebabkan oleh banyaknya perusahaan yang memangkas biaya promosi dan iklan untuk menjaga kesehatan arus kas perusahaan agar bisa berhasil melewati krisis ini.

Indonesia di hadapkan dengan banyak masalah terkait aspek ekonomi akibat dari Covid-19. Ekonomi di Indonesia pada tahun 2020 tumbuh negatif, angka pengangguran dan kemiskinan meningkat. Berdasarkan perhitungan Year on Year pertumbuhan ekonomi pada triwulan pertama tahun 2020 menunjukkan adanya pelemahan dengan hanya mencapai 2,97\% dibandingkan capaian triwulan pertama tahun 2019 yang sebesar $5.07 \%$. Data pada triwulan kedua juga kurang bersahabat dengan menunjukkan kemunduran yang dalam sebesar $-5,32 \%$, terburuk sejak tahun 1999. Data pada triwulan ketiga mengalami kontraksi pertumbuhan sebesar 3,49\%, sedangkan pada triwulan keempat mengalami kontraksi pertumbuhan sebesar 2,19\%. Dampak dari menurunnya 
persentase ekonomi di Indonesia, salah satunya adalah peningkatan angka pengangguran dan penduduk miskin yang disebabkan karena PHK selama masa pandemi Covid-19 (www.bps.go.id). Berikut ditampilkan data mengenai pertumbuhan ekonomi pertahun 2020 berdasarkan data Produk Domestik Bruto (PDB)

Tabel 1 Pertumbuhan Ekonomi Indonesia

\begin{tabular}{cccc}
\hline No. & & Tahun & Persentase \\
\hline 1. & 2014 & \\
2. & 2015 & $5,01 \%$ \\
3. & 2016 & $4,88 \%$ \\
4. & 2017 & $5,03 \%$ \\
5. & 2018 & $5,07 \%$ \\
6. & 2019 & $5,17 \%$ \\
7. & 2020 & $5,02 \%$ \\
\hline
\end{tabular}

Sumber: www.bps.go.id (2021)

Perusahaan penyedia jasa periklanan atau advertising agency, sebelum pandemic Covid ini memang berkembang cukup pesat. Pada saat ini di Indonesia dapat dengan mudah menemukan perusahaan advertising agency ini yang biasanya menyediakan jasa untuk perusahaan maupun perorangan untuk mempromosikan produk usahanya (www.cnnindonesia.com). Beberapa hal yang menyebabkan perusahaan advertising agency di Indonesia berkembang karena banyaknya kebutuhan oleh perusahaan yang bersakala besar maupun kecil yang ingin memasarkan produk atau jasa yang dihasilkan. Dengan semakin ketatnya persaingan dalam produk usaha dan jasa yang ditawarkan oleh perusahaan dalam meningkatkan jangkauan pasar dan meningkatkan kesadaran konsumen terhadap sebuah merek maka peranan dari perusahaan dibidang agensi periklanan semakin besar dan diperlukan. Dengan semakin sering dan banyaknya iklan yang ditanyangkan atau ditampilkan maka akan semakin besar pula kemungkinan produk atau jasa tersebut dibeli oleh konsumen. Dengan semakin banyaknya omset dan penjualan maka akan meningkatkan profitabilitas dan kesehatan perusahaan secara umum (www.cnnindonesia.com).

Kinerja karyawan merupakan hasil dari apa yang telah dicapai di tempat kerja dan sangat bergantung pada tingkat kinerja individu. Masalah krusial yang terkait dengan manajemen talenta di berbagai organisasi muncul sebagai tantangan sumber daya manusia utama yang dihadapi perusahaan di berbagai industri (Mensah et al., 2016). Menurut Iqbal et al., (2015), kepemimpinan memegang peranan yang penting dalam mengelola sumber daya manusia di perusahaan. Keberhasilan seorang pemimpin dalam mengelola karyawan akan mempengaruhi keberhasilan perusahaan secara umum. Kemampuan seorang pemimpin yang tegas dan mampu menjadi panutan bagi bawahan memberikan pengaruh yang besar dalam keberhasilan dan kesuksesan sebuah organisasi. Apabila pemimpin tidak mampu mengelola bawahan dengan baik maka tujuan perusahaan akan sulit tercapai karena bisa jadi bawahan akan bekerja dengan caranya masing-masing. Keputusan tepat yang diambil oleh seorang pemimpin ditentukan oleh kemampuannya dalam menganalisa dan mengevaluasi permasalahan yang ada. Solusi atas permasalahan ini bisa saja didapatkan dari bawahan yang mempunyai tingkat partisipasi yang tinggi dalam pengambilan keputusan. 


\section{LANDASAN TEORI}

Gaya kepemimpinan sering dianggap sebagai salah satu faktor vital yang dapat meningkatkan komitmen karyawan dan dipandang sebagai kawat hidup untuk pencapaian tujuan organisasi. Penelitian Abasilim et al., (2019) ini membahas hubungan antara gaya kepemimpinan dan komitmen karyawan pada 230 responden di kantor komisi pemerintahan Nigeria. Data survei dikumpulkan dari karyawan organisasi, dan hasil penelitian menunjukkan bahwa terdapat hubungan positif yang signifikan antara gaya kepemimpinan dengan komitmen karyawan. Penelitian Friday \& Sunday, (2019) ini menyelidiki hubungan antara manajemen bakat dan komitmen pekerja pada perusahaan minyak dan gas di Nigeria. Karyawan dari sepuluh perusahaan minyak dan gas disurvei dengan menggunakan sampel acak sederhana. Populasi yang terdiri dari 125 manajer dan supervisor disurvei dari sepuluh perusahaan minyak dan gas di negara bagian Rivers, Nigeria sedangkan sampel 95 menggunakan tabel penentuan ukuran sampel Krejcie dan Morgan. Penelitian ini menemukan bahwa manajemen bakat memiliki hubungan positif signifikan dengan komitmen pekerja. Disimpulkan bahwa manajemen bakat yang diukur dalam hal daya tarik bakat, pengembangan bakat, dan retensi bakat meningkatkan komitmen pekerja di perusahaan minyak dan gas di Nigeria.

Tujuan dari penelitian Nasab \& Afshari, (2019) ini adalah untuk mengetahui pengaruh kepemimpinan terhadap kinerja karyawan dan untuk menguji peran mediasi dari komitmen organisasi. Data untuk penelitian ini diperoleh dari semua karyawan (216) agen pariwisata di provinsi Guilan (Iran) dengan menggunakan 19 pertanyaan dalam survei. Secara total, 173 kuesioner dikembalikan, menghasilkan tingkat tanggapan 80 persen. Model mediasi diuraikan dan diuji menggunakan pemodelan persamaan struktural. Hasil penelitian menunjukkan bahwa leadership berpengaruh signifikan terhadap employee performance dan organizational commitment. Temuan lebih lanjut menunjukkan pentingnya hubungan antara organizational commitment dan employee performance yang menegaskan peran mediasi organizational commitment.

Penelitian Vito et al., (2018) ini difokuskan pada hubungan antara manajemen bakat dan komitmen karyawan bank di Port Harcourt, Nigeria. Data primer diperoleh dengan menggunakan kuesioner sebagai instrumen penelitian. Populasi penelitian 209 responden dari lima bank di Port Harcourt. Setelah dilakukan olah data, hanya 124 responden yang layak untuk dianalisis. Temuan penelitian mengkonfirmasi bahwa manajemen bakat secara signifikan memprediksi komitmen karyawan di Port Harcourt. Hasil penelitian menyimpulkan bahwa strategi kepemimpinan berpengaruh positif dan signifikan terhadap kinerja organisasi. Penelitian Mensah et al., (2016) menggabungkan wawasan dari pertukaran sosial dan teori pensinyalan, tujuan dari penelitian ini ada dua: pertama, untuk menyelidiki hubungan antara praktik manajemen bakat dan empat dimensi kinerja karyawan yang berbakat; dan, kedua, untuk memeriksa peran mediasi dari kepuasan kerja dan komitmen efektif dalam perselisihan hubungan dalam konteks perbankan di Ghana. Pemodelan kutipan struktural digunakan untuk data survei dari 322 karyawan yang merupakan bagian dari persalinan di sektor perbankan Ghana. Temuan makalah menunjukkan bahwa praktik manajemen bakat meningkatkan kinerja tugas karyawan yang berbakat, kontekstual dan adaptif, sedangkan itu mengurangi perilaku kontraproduktif. Kedua, sikap kerja karyawan berbakat kepuasan kerja dan komitmen afektif sebagian memediasi hubungan antara praktik manajemen bakat dan empat dimensi kinerja karyawan berbakat. 
Pengaruh gaya kepemimpinan terhadap komitmen karyawan untuk organisasi belum diteliti secara memadai di Parastatal, Afrika Selatan. Oleh karena itu, diperlukan pemahaman yang lebih baik tentang hubungan antara gaya kepemimpinan dan sikap yang berhubungan dengan pekerjaan untuk mengembangkan gaya kepemimpinan yang akan mendorong komitmen organisasi. Studi (Garg \& Ramjee, 2013) ini menguji hubungan antara gaya kepemimpinan, dan komitmen karyawan. Manajer dan bawahannya berpartisipasi dalam penelitian ini. 348 kuesioner dibagikan, 58 untuk manajer dan 290 untuk bawahan mereka. Data akhir untuk analisis termasuk tanggapan dari 197 peserta (34 manajer, dan 163 bawahan. Tujuan dari penelitian Hamid et al., (2020) ini adalah untuk menguji pengaruh kepemimpinan dan manajemen bakat terhadap kinerja karyawan hotel. Penelitian ini juga menguji pengaruh mediasi komitmen karyawan dalam hubungan antara kepemimpinan etis, manajemen bakat dan kinerja karyawan. Teori pertukaran anggota pemimpin dan teori pertukaran sosial telah digunakan sebagai teori yang mendasari kerangka dalam penelitian ini. Data dikumpulkan melalui kuesioner online yang dibagikan kepada karyawan front desk yang bekerja di hotel bintang satu, bintang dua dan bintang tiga di sekitar Malaysia khususnya di Penang dan Kuala Lumpur. Sebanyak 150 kuesioner yang dapat digunakan dikumpulkan dari responden yang ditargetkan. Ukuran sampel telah diidentifikasi menggunakan perangkat lunak PLS digunakan untuk menganalisis data. Temuan penelitian ini menunjukkan bahwa kepemimpinan etis tidak memiliki hubungan yang signifikan dengan komitmen karyawan, sedangkan manajemen bakat memiliki hubungan yang positif dan signifikan dengan komitmen karyawan. Studi ini juga mengkonfirmasi efek mediasi dari komitmen karyawan antara hubungan manajemen bakat dan kinerja karyawan.

Manajemen bakat adalah masalah mendasar bagi perusahaan sektor swasta dan publik. Penelitian Arocas dan Lara, (2020) ini menganalisis dampak manajemen bakat terhadap kinerja layanan dan peran mediasi dari komitmen organisasi. Data dianalisis dari 104 pegawai pemerintah di Spanyol. Hasilnya mengungkapkan bagaimana komitmen organisasi merupakan variabel mediasi total dalam hubungan kausal antara manjemen bakat dengan kinerja karyawan. Hasilnya melibatkan perhatian untuk meningkatkan layanan melalui profesional yang menyediakannya, yang pada gilirannya memerlukan pengelolaan orang dengan cara yang berbeda, lebih fleksibel, tidak terlalu birokratis, dan lebih berorientasi pada masyarakat..

\section{Pengaruh Leadership terhadap Employee Commitment}

Menurut Hamid et al., (2020), pemimpin etis akan menjadi panutan ketika mereka menunjukkan integritas dan menetapkan standar etika yang tinggi untuk diri mereka sendiri serta orang lain. Dengan demikian, karyawan lebih cenderung mengikuti dan menginternalisasi perilaku yang didorong oleh nilai dari pemimpin etis pemodelan peran mereka. Pemodelan peran memengaruhi perilaku etis melalui sarana motivasi dan informasional. Pemimpin sebagai teladan memotivasi perilaku etis dengan menunjukkan jenis tindakan yang ingin mereka promosikan dan beri penghargaan. Selain itu, pemimpin juga berfungsi sebagai panduan informasi untuk perilaku yang dapat diterima. Para peneliti juga menyarankan bahwa kepemimpinan etis membentuk perilaku pengikut melalui proses pertukaran sosial. Teori pertukaran sosial mengusulkan bahwa norma timbal balik atau kewajiban yang dirasakan untuk membalas kebaikan mendasari banyak hubungan sosial (Kumudha, 2016).

\section{Pengaruh Talent Mangement terhadap Employee Commitment}


Manajemen talenta menurut Hamid et al., (2020), adalah tanggung jawab untuk mengidentifikasi karyawan yang memiliki keterampilan dan kompetensi yang baik untuk mengikuti persaingan dan tantangan kerja. Banyak praktik telah digunakan oleh departemen sumber daya manusia untuk mempekerjakan dan mencari karyawan berbakat sehingga mereka hanya perlu memolesnya agar dapat memberikan kinerja yang baik. Tujuan dari manajemen bakat adalah untuk memaksimalkan karyawan yang berbakat dan memanfaatkannya dengan tepat. Akademisi dan praktisi setuju bahwa manajemen bakat terus menjadi salah satu prioritas bagi organisasi di seluruh dunia, karena dapat mewakili sumber keunggulan kompetitif yang berkelanjutan dalam lingkungan pasar yang sangat dinamis dan seringkali tidak menentu. Manajemen talenta juga dapat didefinisikan sebagai salah satu dari kegiatan dan proses terkait HRM yang terdiri dari identifikasi sistematis dari posisi kunci yang berkontribusi pada keunggulan kompetitif berkelanjutan organisasi, pengembangan kumpulan talenta berpotensi tinggi dan berkinerja tinggi petahana untuk mengisi peran ini, pengembangan arsitektur sumber daya manusia yang berbeda untuk memfasilitasi pengisian posisi ini dengan petahana yang kompeten, dan untuk memastikan komitmen berkelanjutan mereka terhadap organisasi.

\section{Pengaruh Employee Commitment terhadap Employee Performance}

Hamid et al., (2020), mendefinisikan komitmen karyawan sebagai keadaan psikologis yang menandakan kekuatan hubungan karyawan dengan organisasi dan mencerminkan niat untuk mempertahankan hubungan tersebut. Komitmen karyawan adalah topik yang populer dalam penelitian manajemen karena bertindak seperti ikatan yang menghubungkan karyawan dengan organisasi mereka dan ini dapat memiliki pengaruh yang signifikan terhadap kinerja karyawan. Upaya penelitian difokuskan pada dua aspek komitmen karyawan; komitmen sikap, yang berpusat pada bagaimana karyawan berpikir tentang hubungan mereka dengan organisasi; dan komitmen perilaku, yang menyatu pada bagaimana seorang individu dapat menjadi terkunci ke dalam organisasi tertentu. Konseptualisasi ini menggambarkan sifat kompleks dari konstruksi komitmen karyawan dengan membantu model afiliasi karyawan dengan, dan disposisi terhadap, organisasi pemberi kerja mereka.

\section{Leadership berpengaruh signifikan pada Employee Performance dan dimediasi oleh Employee Commitment}

Menurut Hamid et al., (2020), tingkat komitmen karyawan yang lebih tinggi mengarah pada keyakinan yang kuat dan penerimaan terhadap tujuan dan nilai organisasi; keinginan yang kuat untuk mengerahkan upaya terbaik untuk organisasi; dan keinginan yang kuat untuk tetap sebagai anggota organisasi. Komitmen karyawan juga merupakan prediktor yang jauh lebih baik dari pergantian staf daripada kehadiran, kepuasan kerja, kinerja tingkat individu dan kelompok, loyalitas karyawan dan efektivitas organisasi secara keseluruhan. Komitmen karyawan menjelaskan bagaimana karyawan dengan sikap kerja positif menciptakan kecenderungan untuk terlibat atau berkontribusi pada masukan yang diinginkan ke dalam peran kerja seorang karyawan.

\section{Talent Management berpengaruh signifikan pada Employee Performance dan dimediasi oleh Employee Commitment}

Penelitian sebelumnya menemukan korelasi positif antara komitmen dan kinerja karyawan. Karyawan yang puas umumnya memiliki sikap yang lebih positif yang membantu mereka untuk bekerja lebih baik (Mowday et al., 2013), dan mereka sangat 
termotivasi, memiliki semangat kerja yang baik, dan bekerja lebih efektif dan efisien. Oleh karena itu, kinerja karyawan mencakup perilaku yang relevan dengan tujuan organisasi yang berada di bawah kendali individu karyawan, wajar untuk mengharapkan karyawan yang memiliki komitmen yang lebih kuat untuk pekerjaan dan organisasi untuk bekerja lebih keras daripada mereka yang tidak mempunyai komitmen yang kuat.

Perumusan hipotesis penelitian sebagai berikut:

H1: Leadership berpengaruh signifikan pada employee commitment

$\mathrm{H} 2$ : Talent management berpengaruh pada employee commitment

H3: Employee commitment berpengaruh pada employee performance

H4: Employee commitment memediasi hubungan leadership terhadap employee performance

H5: Employee commitment memediasi hubungan talent management terhadap employee performance

\section{METODOLOGI PENELITIAN}

Penelitian ini termasuk dalam penelitian dasar yang merupakan jenis penlitian yang meneliti hubungan sebab akibat pada lingkungan akademisi. Jadi model yang dikembangkan dan diteliti dalam penelitian ini merupakan pengembangan sebuah teori dalam bidang keilmuan tertentu yang ditelusuri hubungan antar variabel penelitian yang telah disusun dalm kerangka penelitian. Menurut Sugiyono (2016) metode penelitian yang digunakan ini termasuk dalam metode kualitatif, yaitu sebuah metode penelitian yang bertujuan untuk meneliti kondisi obyek yang alamiah dimana peneliti diposisikan sebagai instrumen kunci. Dan menurutnya jenis penelitian ini termasuk dalam kategori penelitian kuantitatif deskriptif, yaitu sebuah penelitian yang menggantungkan kesimpulan dari nilai dan angka yang didapat dari hasil uji data.

Karyawan dari perusahaan agen periklanan di Batam menjadi objek dalam penelitian ini. Populasi yang mencakup seluruh karyawan perussahaan agen periklanan yang paling besar di Batam dan untuk sampel penelitian ditetapkan dari lima perusahaan agen periklanan di Batam. Berdasarkan rumusan dari Hair et al., (2014) jumlah sampel minimum sebagai responden penelitian adalah sebanyak 10 kuesioner untuk setiap pertanyaan dalam kuesioner. Karena pertanyaan dalam kuesioner berjumlah 19 maka responden minimumnya adalah 190, namun untuk mengantisipasi kuesioner yang tidak kembali maka sebanyak 250 kuesioner disebarkan pada 5 perusahaan agen periklanan di Batam dengan masing-masing 50 responden.

\section{HASIL PENELITIAN}

Setelah disebarkan kepada responden karyawan agen periklanan di Batam dengan google form, maka didapatkan sebanyak 250 kuesioner yang sudah diisi dan bisa direkap untuk uji data selanjutnya. Pengujian ini memberikan bukti bahwa terdapat pengaruh langsung dan tidak langsung diantara variabel yang dikaji. Hasil uji menunjukkan hubungan yang signifikan bila nilai t-statistic melebihi 1,96 dan $\mathrm{P}$ values lebih kecil dari 0,05 .

Tabel 2

Hasil Uji Pengaruh Langsung dan Tidak Langsung 


\begin{tabular}{|l|r|r|c|}
\hline \multicolumn{1}{|c|}{ Variabel $(\mathrm{X} \rightarrow \mathrm{Y})$} & T-Statistics & P Values & Kesimpulan \\
\hline $\begin{array}{l}\text { Leadership }->\text { Employee } \\
\text { Commitment }\end{array}$ & 3.310 & 0.001 & H1 Signifikan \\
\hline $\begin{array}{l}\text { Talent Management }->\text { Employee } \\
\text { Commitment }\end{array}$ & 5.436 & 0.000 & H2 Signifikan \\
\hline $\begin{array}{l}\text { Employee Commitment }->\text { Employee } \\
\text { Performance }\end{array}$ & 10.857 & 0.000 & H3 Signifikan \\
\hline $\begin{array}{l}\text { Leadership -> Employee } \\
\begin{array}{l}\text { Commitment }->\text { Employee } \\
\text { Performance }\end{array}\end{array}$ & 3.011 & 0.003 & H4 Signifikan \\
\hline $\begin{array}{l}\text { Talent Management }->\text { Employee } \\
\begin{array}{l}\text { Commitment }->\text { Employee } \\
\text { Performance }\end{array}\end{array}$ & & & \\
\hline
\end{tabular}

Sumber : Data primer diolah (2021)

\section{KESIMPULAN}

Berdasarkan hasil uji $\mathrm{H} 1$ diketahui bahwa nilai T-statistic nya adalah 3.310 dengan nilai $P$ values sebesar 0.001 sehingga dapat disimpulkan terdapat pengaruh antara variable leadership terhadap employee commitment. Artinya semakin tinggi dan bagus gaya kepemimpinan seorang pemimpin dalam sebuah organisasi maka akan semakin meningkatkan komitmen karyawan pada organisasi tersebut. Berdasarkan hasil uji $\mathrm{H} 2$ diatas diketahui bahwa nilai $\mathrm{T}$-statistic nya adalah 5.436 dengan nilai $\mathrm{P}$ values sebesar 0.000 sehingga dapat disimpulkan terdapat pengaruh antara variabel talent management terhadap employee commitment. Hal ini menunjukkan bahwa semakin bagus pengelolaan sumber daya manusia disebuah organisasi maka akan mampu meningkatkan komitmen para karyawan terhadap organisasi dimana dia berada. Berdasarkan hasil uji diatas diketahui bahwa nilai T-statistic $\mathrm{H} 3$ adalah 10.857 dengan nilai $\mathrm{P}$ values sebesar 0.000 sehingga dapat disimpulkan terdapat pengaruh antara variabel employee commitment terhadap employee performance. Hal ini menunjukkan bahwa komitmen organisasi karyawan pada perusahaan dimana ia bekerja akan mampu meningkatkan kinerja dalam perusahaan tersebut dimana karuawanm merasa bagian penting dari perusahaan dan akan memberikan kinerja terbaiknya pada perusahaan.

Berdasarkan hasil uji diatas diketahui bahwa nilai T-statistic $\mathrm{H} 4$ adalah 3.011 dengan nilai $\mathrm{P}$ values sebesar 0.003 sehingga dapat disimpulkan terdapat pengaruh yang signifikan antara variabel leadership terhadap employee performance dengan employee commitment sebagai variabel mediasi. Berdasarkan hasil uji diatas diketahui bahwa nilai T-statistic H5 adalah 4.768 dengan nilai $\mathrm{P}$ values sebesar 0.000 sehingga dapat disimpulkan bahwa terdapat pengaruh yang signifikan antara variabel talent management terhadap employee performance dengan employee commitment sebagai variabel mediasi.

\section{DAFTAR PUSTAKA}

Abasilim, U. D., Gberevbie, D. E., \& Osibanjo, O. A. (2019). Leadership Styles and Employees' Commitment: Empirical Evidence From Nigeria. SAGE Open, 9(3). 
https://doi.org/10.1177/2158244019866287

Hamid, M.R.A., Rahim, A.N.F., \& Salamzadeh, Y. (2020). Influence of Ethical Leadership and Talent Management on Employee Performance: Does Employee Commitment Matter in Malaysian Hotel Industry? International Journal of Human Resource Studies, 10(3), 77. https://doi.org/10.5296/ijhrs.v10i3.17266

Alsheikh, G. A. A., Halim, M. S. B. A., Shafeeq, M., Alremawi, A., \& Tambi, A. M. B. A. (2017). The mediating role of organizational culture on the relationship between employee performance and antecedents in the hotel sector. Journal of Reviews on Global Economics, 6, 489-497. https://doi.org/10.6000/1929-7092.2017.06.49

Andrew, A. (2017). Employees' Commitment and Its Impact on Organizational Performance. Asian Journal of Economics, Business and Accounting, 5(2), 1-13. https://doi.org/10.9734/ajeba/2017/38396

Friday, E. O., \& Sunday, M. (2019). Talent Management and Workers' Commitment. SEISENSE Journal of Management, 2(3), 1-15. https://doi.org/10.33215/sjom.v2i3.138

Garg, A. K., \& Ramjee, D. (2013). The Relationship Between Leadership Styles And Employee Commitment At A Parastatal Company In South Africa. International Business \& Economics Research Journal (IBER), 12(11), 1411. https://doi.org/10.19030/iber.v12i11.8180

Nasab, H.A., \& Afshari, L. (2019). Authentic leadership and employee performance: mediating role of organizational commitment. Leadership and Organization Development Journal, 40(5), 548-560. https://doi.org/10.1108/LODJ-01-20190026

Kumudha, A., \& Kj, H. (2016). The relationship between human resource practices and employee retention in private organisations with special reference to Jebel Ali international hospital in Dubai. 2(5).

Mensah, K.J., Bawole,N.J., \& Wedchayanon, N. (2016). Unlocking the "black box" in the talent management employee performance relationship: evidence from Ghana. Management Research Review, 39(12), 1546-1566. https://doi.org/10.1108/MRR08-2015-0190

Latan, G. (2015). Partial Least Square Konsep Teknik dan Aplikasi Menggunakan Program SmartPLS 3.0 (2nd ed.). Badan Penerbit Universitas Diponegoro.

Arocas, R., \& Lara, F. J. (2020). Talent management, affective organizational commitment and service performance in local government. International Journal of Environmental Research and Public Health, 17(13), 1-15. https://doi.org/10.3390/ijerph17134827

Tabouli, E. M. A., Habtoor, N. A., \& Nashief S., M. (2016). The impact of human resources management on employee performance: Organizational commitment mediator variable. Asian Social Science, 12(9), 176-192. https://doi.org/10.5539/ass.v12n9p176

Vito, B., Alagala, M. B., \& Naakuu, K. J. (2018). Talent Management as Predictor of Employee Commitment of Deposit Money Banks in Port Harcourt. International Journal of Social Sciences and Management Research, 4(5), 50-66. 